\title{
Systemic amyloidosis due to unknown multiple myeloma in small bowel pseudo-obstruction: case report
}

Giuseppe Caparrotti ${ }^{1}$, Diego di Maria ${ }^{1}$,Elia Iovane ${ }^{1}$, Clemente Martone ${ }^{1}$, Francesco Graziani ${ }^{1}$, Giuseppina De Falco ${ }^{1}$, Daniela Esposito ${ }^{1}$, Claudio Marotta ${ }^{1}$, Giuseppina Papa ${ }^{1}$, Isidoro Orabona ${ }^{2}$ Davide Albino Rossetti ${ }^{2}$, Nicola Armiento ${ }^{2}$, Gennaro Ferrara ${ }^{2}$, Pasquale Pezzella

\begin{abstract}
Amyloidosis is a pathologic diagnosis characterized by extracellular deposition of insoluble protein fibrils in various organs and tissues. There are two main forms of amyloidosis, primary amyloidosis, and secondary amyloidosis. Gastrointestinal involvement is common in both amyloidosis forms.

We describe the case of a 78-year-old woman taken to the operating room for small bowel obstruction, found to have pseudo-obstruction and enteritis. Exploratory laparotomy revealed gastric mass and histological examen shorwed extensive amyloid deposition consistent with amyloidosis. Hematological evaluation revealed unknown multiple myeloma. This case report and literature data suggest to perform a hematological examination in patients with amyloidosis diagnosis to exclude a multiple myeloma or other plasma cell disorders.
\end{abstract}

Keywords: Myeloma; Amyloidosis; Pseudo-obstruction; Hypogammaglobulinemia; Congo red stain

Amiloidosi sistemica dovuta a mieloma multiplo sconosciuto in paziente con pseudo-ostruzione intestinale: segnalazione di un caso

CMI 2016; 10(1): 15-18

http://dx.doi.org/10.7175/cmi.v10i1.1213

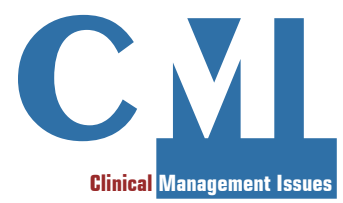

Case report
Division of Hematology,

San Giuseppe

Moscati Hospital,

Aversa (CE), Italy

2 Division of Minimally

Invasive Surgery and

Endolaparoscopy, San

Giuseppe Moscati

Hospital, Aversa

(CE), Italy

\section{INTRODUCTION}

Amyloidosis is a pathologic diagnosis characterized by extracellular deposition of insoluble protein fibrils in various organs and tissues. These proteins possess the ability to bind Congo red stain and appear apple-green under polarized light [1,2]. There are two main forms of amyloidosis, primary amyloidosis (AL) and secondary amyloidosis (AA). AL amyloidosis is characterized by deposition of immunoglobulin light chains or their fragments, produced by a clonal population of plasma cells in the bone marrow as is in multiple myeloma (MM), monoclonal gammopathy of undetermined significance (MGUS) and others plasma cells disorders. AA is characterized by deposition of amyloid in tissues secondary to chronic inflammatory diseases (rheumatoid arthritis, inflammatory bowel diseases) [3], chronic infections and neoplasms such as Hodgkin lymphoma and renal cell carcinoma [4]. AL amyloidosis is the most common type of systemic amyloidosis. Clinical presentation of AL amyloidosis is characterized by vague and non-specific symptoms. The organs frequently affected are kidney, heart, liver, autonomic nervous system, soft

Why we describe this case

A surgical problem hid a hematologicall internal medicine diagnosis. Therefore a multidisciplinary management is very important to make the correct diagnosis
Corresponding author Giuseppe Caparrotti U.O.C. Ematologia, Ospedale

S. Giuseppe Moscati Via Gramsci 1, 81031 Aversa (CE), Italy.

Phone/Fax 081.500.15.28 gcapar@libero.it

Disclosure

The authors declare they have no competing financial interests

concerning the topics of this article 


\begin{tabular}{|l|c|c|}
\multicolumn{1}{|c}{ Parameter } & Values detected & Normal values \\
\hline Hemoglobin $(\mathrm{g} / \mathrm{dl})$ & 11.6 & $12-17$ \\
Total proteins $(\mathrm{g} / \mathrm{dl})$ & 5.4 & $6.4-8.3$ \\
Cholinesterases (UI/L) & 3890 & $4,700-14,000$ \\
\hline
\end{tabular}

Table I. First laboratory tests: main results

tissues, therefore the suspect diagnosis of AL amyloidosis should be considered in patients with proteinuria, cardiomyopathy, neuropathy, hepatomegaly, macroglossia, en-

\begin{tabular}{|l|c|c|}
\hline \multicolumn{1}{|c|}{ Parameter } & Values detected & Normal values \\
\hline Bence Jones protein-k chains & Present & Absent \\
lgG-K/urine (mg/l) & 2570 & $0-10$ \\
IgG-L/urine (mg/l) & 10.4 & $0-5$ \\
Ratio K/L & 247.1 & $0.7-6.2$ \\
\hline
\end{tabular}

Table II. Urine tests: main results

\begin{tabular}{|l|c|c|}
\hline \multicolumn{1}{|c|}{ Parameter } & Values deteeted & Normal values \\
\hline Gammaglobulin (g/d) & 0.22 & $0.80-1.35$ \\
$\lg \mathrm{G}(\mathrm{g} / \mathrm{l})$ & 3 & $7-16$ \\
$\operatorname{lgA}(\mathrm{g} / \mathrm{l})$ & 0.5 & $0.7-4$ \\
$\lg \mathrm{g}(\mathrm{g} / \mathrm{l})$ & 4.0 & $0.4-2.3$ \\
Beta2-microglobulin (mg/l) & 2.4 & $0.2-2.3$ \\
\hline
\end{tabular}

Table III. Serum protein electrophoresis: main results docrinopathies [5]. Gastrointestinal involvement is common in AL (70\% of cases) and AA (55\% of cases) amyloidosis [6]. Systemic amyloidosis is a rare disease and the patients ne; additionally serum free light chain assay is important in diagnosis, monitoring and prognosis of AL amyloidosis [9].

We report a case of AL amyloidosis with gastric and small bowel involvement on a patient who was unknown MM.

\section{CASE REPORT}

A 78-year-old woman was admitted to our hospital on September 2014 with a history of abdominal pain and clinical signs of intestinal occlusion.

Laboratory tests showed a mild normochromic normocytic anemia, a reduction of total proteins and cholinesterases (Table I).

Electrocardiography showed voltage reduction in all derivations; $\mathrm{CT}$ scan abdomen showed dilatation of small bowel with mesenteric edema and the patient was taken to the operating room.

Laparotomy exploratory revealed a dilatation of small bowel with mesenteric edema by pseudo-obstruction and gastric mass suspected to be of neoplastic etiology. Partial gastrectomy was performed and patient was referred in chirurgic division. Histological examination showed deposition of eosinophilic material in gastric mucosa, submucosa and muscularis mucosae. The deposit had an apple-green birefringence by Congo red stain under polarized light. The diagnosis of amyloidosis was made. Periumbilical fat biopsy confirmed systemic amyloidosis diagnosis.

Hematologists were consulted and various examinations were executed, revealing the presence in urine of Bence Jones protein- $\mathrm{k}$ chains (Table II). Serum protein electrophoresis showed hypogammaglobulinemia, no monoclonal component (Table III), while bone marrow fine-needle aspiration showed plasmacellular involvement rate in $40 \%$ of total cells.

The final diagnosis was therefore a MM and systemic AL. Chemotherapy protocol VMP (bortezomib, melphalan, prednisone) was programmed but the patient died by cardiac failure, few days after MM diagnosis, before the therapy was started.

To suspect in patient with amyloidosis a MM

We suggest to make a hematological examination in patients with amyloidosis diagnosis to exclude a MM or others plasma cell disorders; bone marrow fine-needle aspiration to make indispensable although monoclonal gammopathy absence

often present non-specific gastrointestinal syms: abdominal pain, gastrointestina AL monstration of amyloid deposits with bone marrow biopsy, electrophoresis and immunofixation in the serum and uri- 


\section{DISCUSSION}

AL amyloidosis rarely presents without systemic symptoms. The kidneys and heart are often involved, but the nervous system, lungs, liver, soft tissue and gastrointestinal tract can be involved. Gastrointestinal involvement is common in AL (70\% of cases) and AA (55\% of cases) amyloidosis [6]. Pseudo-obstruction have been described in few patients with AL and AA amyloidosis $[10,11]$. Intestinal pseudo-obstruction is characterized by symptoms and signs of mechanical obstruction in the absence of any organic occlusion of the lumen.

We report a case of small bowel pseudoobstruction secondary to AL amyloidosis in patient with unknown MM. Intestinal pseudo-obstruction is caused by amyloid deposition in muscular or nervous tissue of gastrointestinal tract causing myopathy or neuropathy, respectively [10].

$\mathrm{AL}$ amyloidosis is often associated with MM, smoldering multiple myeloma, MGUS [12].

About $10 \%$ of AL patients may have MM at the time of diagnosis and $30 \%$ of MM patients may have amyloid deposition at the time of diagnosis [13]. A patient with myeloma may have or develop AL amyloidosis, but it is rare for a patient with AL amyloidosis, who does not have myeloma at presentation, to progress in myeloma. In this case report the patient received occasionally diagnosis of amyloidosis and, after hematological examinations, a unknown MM was diagnosed.

The intestinal obstruction was the first symptom of AL in a patient who had a MM probably for some time and who subsequently developed amyloidosis. As reported in the literature [7,8], the onset of amyloidosis in a patient with $\mathrm{MM}$ is much more common than the contrary.

Early diagnosis and identification of the type of amyloidosis are critical in the care of patients with this disease, to allow the reversal of organ damage and a better tolerability of adverse effects of therapy.

In conclusion, this case report and literature data suggest to perform a hematological examination in patients with amyloidosis diagnosis to exclude a MM or other plasma cell disorders; furthermore the importance of a multidisciplinary approach to the amyloidosis is confirmed.

\section{REFERENCES}

1. Glenner GG. Amyloid deposits and amyloidosis: the beta-fibrilloses. NEngl J Med 1980; 302: 1333-43; http://dx.doi.org/10.1056/NEJM198006123022403

2. Eastwood H, Cole KR. Staining of amyloid by buffered Congo red in 50 percent ethanol. Stain Technol 1971; 46: 208-9; http://ncbi.nlm.nih.gov/pubmed/4105512

3. Falk RH, Conenzo RL, Skinner M. The systemic amyloidosis. N Engl J Med 1997; 337: 898909; http://dx.doi.org/10.1056/NEJM199709253371306

4. Ogawa S, Murakami T, Inoshima Y, et al. Effect of heating on the stability of amyloid A (AA) fibrils and the intra- and cross-species transmission of AA amyloidosis. Amyloid 2015; 22: 23643; http://dx.doi.org/10.3109/13506129.2015.1095735

5. Merlini G, Seldin DC, Gertz MA. Amyloidosis: pathogenesis and new therapeutic options. $J$ Clin Oncol 2011; 29: 1924-33; http://dx.doi.org/10.1200/JCO.2010.32.2271

6. Ebert EC, Nagar M. Gastrointestinal manifestations of amyloidosis. Am J Gastroenterol 2008; 103: 776-87; http://dx.doi.org/10.1111/j.1572-0241.2007.01669.x

7. Lin X, Mao Y, Qi Q, et al. Primary systemic amyloidosis initially presenting with digestive symptoms: a case report and review of the literature. Diagn Pathol 2015; 10: 174; http://dx.doi. org/10.1186/s13000-015-0407-9

8. Van Gameren II, Hazenberg BP, Bijzet J, et al. Diagnostic accuracy of subcutaneous abdominal fat tissue aspiration for detecting systemic amyloidosis and its utility in clinical practice. Arthritis Rheum 2006; 54: 2015-21; http://dx.doi.org/10.1002/art.21902

9. Bhole MV, Sadler R, Ramasamy K. Serum-free light-chain assay: clinical utility and limitations. Ann Clin Biochem 2014;51:528-42. http://dx.doi.org/10.1177/0004563213518758

10. Koppelman RN, Stollman NH, Baigorri F, et al. Acute small bowel pseudo-obstruction due to AL amyloidosis: a case report and literature review. Am J Gastroenterol 2000; 95: 294-6; http:// dx.doi.org/10.1111/j.1572-0241.2000.01712.x 
11. Cowan AJ, Skinner M, Seldin DC, et al. Amyloidosis of the gastrointestinal tract: a 13-year, single-center, referral experience. Haematologica 2013; 98: 141-46; http://dx.doi.org/10.3324/ haematol.2012.068155

12. Rajkumar SV, Dispenzieri A, Kyle RA.Monoclonal gammopathy of undetermined significance, Waldentrom macroglobulinemia, AL amyloidosis, and related plasma cell disorders: diagnosis and treatment. Mayo Clin Proc 2006; 81:693-703; http://dx.doi.org/10.4065/81.5.693

13. Rajkumar SV, Gertz MA, Kyle RA. Primary systemic amyloidosis with delayed progression to multiple myeloma. Cancer 1998; 82: 1501-5; http://dx.doi.org/10.1002/(SICI)10970142(19980415)82:8<1501::AID-CNCR11>3.0.CO;2-8 